\title{
A comparison of primidone, propranolol, and placebo in essential tremor, using quantitative analysis
}

\author{
WP GORMAN, R COOPER, P POCOCK, MJ CAMPBELL
}

From the Department of Neurology, Frenchay Hospital, and the Burden Neurological Institute, Bristol, UK

SUMMARY The effects of placebo, propranolol and primidone were compared in 14 patients with essential tremor in a double blind, randomised, crossover study. Objective measures of tremor were obtained using an accelerometer with subsequent spectral analysis. Both propranolol ( $\mathrm{p}<$ $0.01)$ and primidone $(p<0.01)$ gave significant improvement in tremor, but there was no significant difference in improvement between these drugs. Patients with higher dominant frequencies of tremor tended to respond to both drugs, while those with lower frequencies improved on one or other. There was no differential effect between the drugs with the frequency of tremor.

Benign essential tremor is a common condition characterised by tremor with postural and action components. Although benign in terms of its lack of effect on life expectancy, a small percentage of patients suffer serious disability as a result of tremor in the arms and hands, and a larger number find it a significant embarassment. ${ }^{1}$ Propranolol and more recently primidone have been shown to be effective treatments, ${ }^{23}$ but they have not previously been compared in a controlled trial.

\section{Patients and methods}

Nineteen patients with a clinical diagnosis of essential tremor made in a neurology clinic gave informed consent and were included in the study. There were four females and 15 males, with a mean age of 58 years and a mean tremor duration of 16 years. Nine patients had a positive family history and 11 gave a history of improvement in the tremor with alcohol. Patients were excluded from the trial if any of the following were present: cardiac failure, asthma, peripheral vascular disease, diabetes mellitus, or pre-existing requirement for either propranolol or primidone.

\section{Protocol}

The study was double blind, randomised, and cross-

Address for reprint requests: Dr WP Gorman, Department of Neurology, Frenchay Hospital, Bristol BS16 1LE, UK.

Received 8 February 1985 and in revised form 19 April 1985. Accepted 22 April 1985 over in design. Patients were examined, subjective data recorded, and tremor measurements made on each of four occasions; a baseline on no medication, and one for each of the three treatment courses Capsules of identical appearance but containing propranolol, primidone, or lactose as placebo, were given according to the same regime. In order to stari $\overrightarrow{-}$ the primidone at a low dose, an "introductory" cap? sule containing $62.5 \mathrm{mg}$ of primidone for the primidone regime or placebo for the other two was taken on days 1 and 2 . Subsequently the primidone dose was raised by $125 \mathrm{mg}$ every second day to maximum of $250 \mathrm{mg}$ three times daily. The propranolol started at $20 \mathrm{mg}$ and was raised by $20 \mathrm{mg}$ every second day to a maximum of $40 \mathrm{mg}$ three times daily. After 10 days at the maximum dose, tremor and subjective data were recorded and blood taken for drug levels, and the capsules were then withdrawn over 5 days. Patients were requested to avoid alcohol, caffeine and smoking for 16 hours before testing, and were on no other tremor active drugs during the trial.

Measurement of tremor was made using an Entran EGB-125-5-d accelerometer weighing $0.5 \mathrm{~g}$ taped to the dorsum of the middle finger of the more affected hand. The patient was reclining with the arm supported at the forearm and the hand outstretched. Tremor was recorded on a Tandberg Instrumentation Recorder Series 100 tape recorder. A gravimetric calibration was obtained by inverting the accelerometer. Recordings were made for 6 periods each of 80 seconds, with 5 minutes rest between recordings. Tremor was also measured in six normal subjects by the same technique. 
(a) Moderate

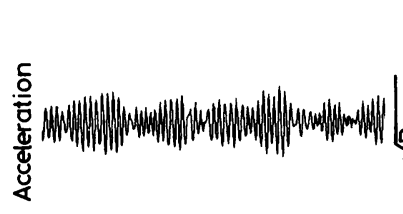

(b) Mild

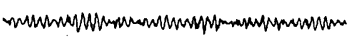

(C) Control
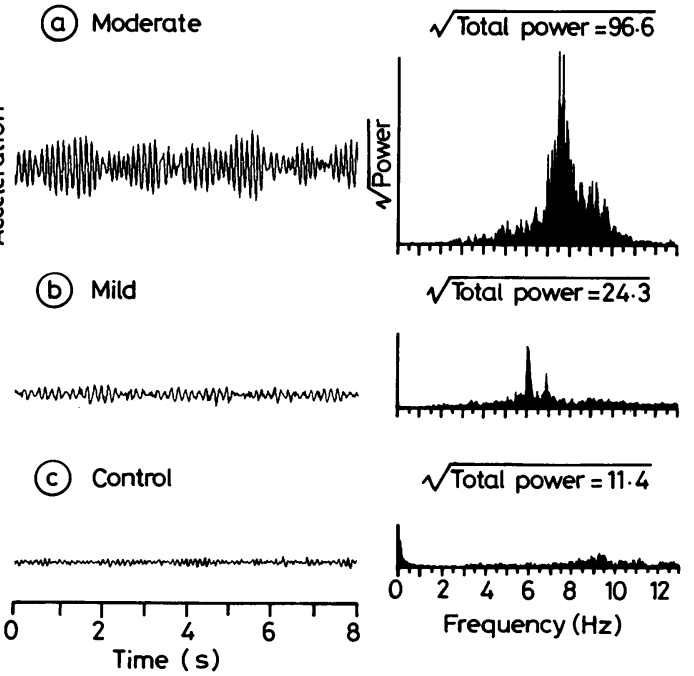

Fig 1 Examples of tremorgrams, tremor values, and power spectra replotted as square root of power against frequency. (a) from a subject with moderate essential tremor, (b) mild essential tremor, (c) a normal subject.

\section{Analysis}

Tremor analysis was performed off line using a PDP-12 computer, with a program carrying out a 1024 point Fourier transform on four consecutive 16 second blocks of data from each 80 second period, after data containing artefact were excluded. An average power spectrum was then obtained and a measure of tremor in the 3 to $1215 / 16 \mathrm{~Hz}$ waveband was obtained by taking the square root of the power in that band. For simplicity the frequency ranges are subsequently described from the lower limit (in- clusive) to the upper limit (exclusive), thus 3 to $12^{15} /{ }_{16} \mathrm{~Hz}$ becomes $3-13 \mathrm{~Hz}$.

\section{Statistics}

These values of tremor on different treatments, expressed as a percentage of the baseline reading, were compared using Student's $t$ test for paired differences across the group. This was done for the values in the frequency range $3-13 \mathrm{~Hz}$, and also when this range was separated into the 10 consecutive intervals of $1 \mathrm{~Hz}$ bandwidth. The $t$ test was also used to compare standardised tremors on different regimes for individual patients.

\section{Results}

Nineteen patients entered the trial. One patient was excluded because the propranolol was probably subtherapeutic, one because of failure to tolerate propranolol, and three because of failure to tolerate primidone. Of the remaining 14 patients, the mean dominant tremor frequency was $6.4 \mathrm{~Hz}$. The primidone levels ranged from 54 to $116 \mu \mathrm{mols} / 1$, and the propranolol levels from 19 to $117 \mathrm{ng} / \mathrm{ml}$. The resting pulse rate fell by a mean of 11 beats per minute on propranolol compared to that on placebo.

When asked which treatment course they preferred, nine patients indicated that of primidone; and five propranolol. One preferred propranolol even though he thought primidone more effective, because of slight drowsiness on the latter. Only two patients indicated the placebo course to be more effective that either one or other of the active drugs, and none preferred it to both.

Examples of "tremorgrams" and the spectrum plotted as square root of power against frequency

Table 1 Comparison of tremor values on placebo, propranolol and primidone

\begin{tabular}{|c|c|c|c|}
\hline Placebo $m \pm s d$ & Propranolol $m \pm s d$ & Primidone $m \pm s d$ & $\begin{array}{l}\begin{array}{l}\text { Baseline } \\
\text { dominant } \\
\text { frequency } f\end{array} \\
4.4\end{array}$ \\
\hline 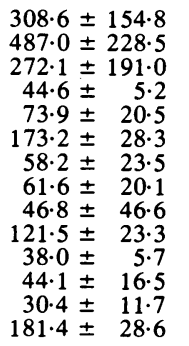 & 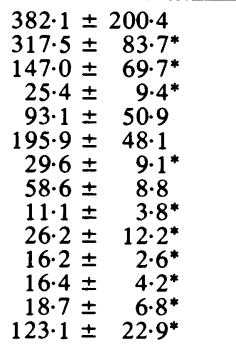 & $\begin{array}{r}477.1 \pm 175.6^{*} \\
414.5 \pm 117.6 \\
219.4 \pm 176.6 \\
42.9 \pm 12.4 \\
43.3 \pm 18.8^{*} \\
93.1 \pm 104.7^{*} \\
35.5 \pm 15.9^{*} \\
28.1 \pm 10.1^{*} \\
41.5 \pm 36.2 \\
63.5 \pm 10.3^{*} \\
20.0 \pm 4.3^{*} \\
33.2 \pm 4.6^{*} \\
22.0 \pm \\
75.0 \pm 23.3^{*}\end{array}$ & $\begin{array}{l}4 \cdot 4 \\
5 \cdot 0 \\
5 \cdot 6 \\
5 \cdot 6 \\
5 \cdot 9 \\
6 \cdot 1 \\
6 \cdot 2 \\
6 \cdot 4 \\
6 \cdot 5 \\
6 \cdot 6 \\
7 \cdot 0 \\
7 \cdot 3 \\
8 \cdot 4 \\
8 \cdot 6\end{array}$ \\
\hline
\end{tabular}

$\mathrm{m} \pm \mathrm{sd}=$ mean \pm standard deviation across 24 recording epochs of tremor expressed as the square root of the power in the $3-13 \mathrm{~Hz}$ waveband for each patient.

$f=$ dominant frequency in power spectrum on baseline recording.

${ }^{*}$ Reduction in tremor value on active drug compared to placebo significant at level p $<0 \cdot 01$ or better using Student's $t$ test. 
Table 2 Comparison of tremor values in different frequency bands

\begin{tabular}{|c|c|c|c|}
\hline $\begin{array}{l}\text { Frequency band } \\
\mathrm{Hz}\end{array}$ & Propranolol vs placebo & $\begin{array}{l}\text { Primidone vs placebo } \\
t\end{array}$ & $\begin{array}{l}\text { Propranolol vs primidone } \\
\text { t! }\end{array}$ \\
\hline \multicolumn{4}{|l|}{ (a) } \\
\hline $3-4$ & $1 \cdot 18$ & 0.45 & 0.21 \\
\hline $4-5$ & 0.36 & 0.46 & 0.11 \\
\hline $5-6$ & 1.62 & 0.24 & 0.88 \\
\hline $6-7$ & $2.83 \dagger$ & $3.67 \ddagger$ & 0.89 \\
\hline $7-8$ & $3 \cdot 26 \ddagger$ & $2 \cdot 27^{*}$ & 0.48 \\
\hline $8-9$ & 2.06 & 0.96 & 0.03 \\
\hline $9-10$ & 0.63 & $2 \cdot 48^{*}$ & $1 \cdot 35$ \\
\hline $10-11$ & 0.06 & $2 \cdot 10$ & 1.33 \\
\hline $11-12$ & 0.28 & 0.66 & 0.25 \\
\hline $12-13$ & $3 \cdot 12 \ddagger$ & $1 \cdot 21$ & 0.46 \\
\hline (b) & & & \\
\hline $3-13$ & $2 \cdot 41^{*}$ & $2 \cdot 74 \dagger$ & $1 \cdot 20$ \\
\hline
\end{tabular}

$t$ ! values from Student's $t$ test-for comparison of standardised tremor values analysed across the group in: (a) separate 1 Hz bands, (b) the 3-13 $\mathrm{Hz}$ range

* Significant at level $\mathrm{p}<0.05 ;$ †significant at level $\mathrm{p}<0.02 ; \ddagger$ significant at level $\mathrm{p}<0.01$.

are shown in fig 1 from the records of patients with moderate and mild essential tremor, and one normal subject. Corresponding data from a severe tremor were not included due to the change in scale required. Absolute tremor values were reduced significantly in 10 patients on propranolol, and nine on primidone, with one patient significantly worse on primidone (table 1). Higher tremor values tended to be associated with lower frequencies, but this did not reach statistical significance using the Spearman's rank correlation coefficient test.

When values of tremor standardised as a percen- tage of baseline tremor were compared across the group for the 3-13 $\mathrm{Hz}$ range, tremor was significantly reduced by propranolol $(p<0 \cdot 01)$ and primidone $(p<0.01)$. When compared to placebo rather than baseline, there was still a significant improvement with both propranolol $(p<0.05)$ and primidone $(\mathrm{p}<0.02)$, (table 2$)$. The mean reduction in this study was to $59.7 \%$ of baseline tremor on propranolol, and to $75.6 \%$ on primidone. There was no significant difference between the tremor on the active drugs. The placebo response was small, with no significant decrease in tremor $(t=1 \cdot 46, \mathrm{n}=14$,

Fig 2 Mean tremor values across the group on the three treatment conditions plotted against the frequency. The tremor value refers to the square root of the power in that $1 \mathrm{~Hz}$ band standardised against the maximum component in the baseline spectrum. 
$\mathrm{p}>0 \cdot 10)$.

When the data from the average spectra were analysed in $1 \mathrm{~Hz}$ bands (table 2), there were significant reductions in the $6-7$ and $7-8 \mathrm{~Hz}$ bands with either drug; much of the power in the power spectrum was concentrated in this range (fig 2 ). In addition there were reductions which reached statistical significance in the $9-10 \mathrm{~Hz}$ band for primidone and the $12-13 \mathrm{~Hz}$ band for propranolol. There was no significant change in the mean dominant frequency across the group on propranolol, but there was a fall in mean dominant frequency from $6.23 \pm$ $1.03 \mathrm{~Hz}$ on baseline measurement to $5.92 \pm 1.17 \mathrm{~Hz}$ on primidone, which was significant on Student's $t$ test $(t=2.80, p<0.02, n=13$. One patient was excluded because of lack of a clear peak frequency on primidone).

Those responding to both drugs had a significantly higher mean dominant frequency $(7.35 \mathrm{~Hz})$ than those responding to one or other $(5.87 \mathrm{~Hz}),(p<$ 0.01 ). However the dominant frequency in individual patients was not associated with a selective advantage for one or other drug.

\section{Discussion}

The drug of choice in essential tremor is propranolol. ${ }^{4}$ However not all patients respond to this drug, and there are many patients, particularly in older age groups, in whom non-selective betaadrenoceptor blocking drugs are contraindicated owing to their bronchoconstrictor and negative inotrope effects. The advent of selective beta-2adrenoceptor blockers may overcome some of these disadvantages and early studies in essential tremor have been encouraging. ${ }^{5}$ Primidone has also been shown to produce a dramatic improvement in some patients, ${ }^{3}$ although probably through a different mechanism involving a central oscillator rather than the peripheral mechanism proposed for betaadrenoceptor blockers. We have used spectral analysis to compare the response of a group of patients to these two drugs and hence to attempt to identify clinical guidelines for prescription of treatment.

When the tremor on a treatment was standardised as a percentage of the baseline tremor, the group showed an improvement both on propranolol at a dose of $40 \mathrm{mg}$ three times daily and on primidone at a dose of $250 \mathrm{mg}$ three times daily. This is in accordance with other reports, ${ }^{8-10}$ although a higher dose of propranolol has sometimes been required. ${ }^{112} \mathrm{We}$ decided to use this dose after discussions with a number of neurologists, who were not happy to proceed directly to a propranolol dose of $240 \mathrm{mg}$ daily for this indication. There was no difference between the tremor on propranolol and that on primidone. When the power spectra were reanalysed considering the power in consecutive bands of $1 \mathrm{~Hz}$ width, the benefit of both drugs was most obvious in the 6-8 $\mathrm{Hz}$ range but this may be a result of the relatively strong contribution from these frequencies to the power spectra. The changes which reach statistical significance in the other two bands occur at frequencies where there is little mean power but also little variation, and these are not thought to be of clinical significance. The absence of a significant change in peak frequency with propranolol is in agreement with previous reports. ${ }^{41}$ However the small fall in dominant frequency with primidone was not found by Findley. ${ }^{10}$ This effect if confirmed would have implications for theories on the mechanisms of essential tremor. In future studies comparing frequency bands an adequate bandwidth would have to be chosen to allow for this change.

It has been proposed that there are four subclasses of essential tremor differing in clinical manifestations and possibly in their pathophysiology. ${ }^{12}$ Of these type 1 is probably due to an enhanced stretch reflex and has a frequency of $8-12 \mathrm{~Hz}$, and type 4 is symptomatic essential tremor associated with other neurological conditions. Type 2 and type 3 are probably caused by central oscillators, and have a tremor frequency in the range $5-7 \mathrm{~Hz}$ and 4-6 Hz respectively. Since the "central" tremors are of relatively low frequency and since primidone acts centrally, we were interested to see if patients with a lower dominant frequency were more likely to have a good response to primidone. This did not happen in our group, but it is notable that patients who had a significant response to both drugs tended to have a higher dominant frequency than those who responded only to one or other. Unfortunately our group of patients was too small to assess this trend in detail, but we feel that it is worth following up in future studies with a larger cohort of patients.

Ten patients showed a response to propranolol and nine responded to primidone, several with dramatic effect. There were frequent complaints of malaise, dizziness and unsteadiness on the first $62 \cdot 5$ $\mathrm{mg}$ of primidone, and two patients withdrew from the trial at this point. Primidone is known to cause more frequent side effects when given for essential tremor than in epilepsy, probably owing to concurrent anticonvulsant therapy in the latter. However after the first dose effects the drug was well tolerated, and when asked which of the double blind regimes they preferred, nine referred to primidone and four to propranolol. Data on age, family history, duration of tremor, response to alcohol, and clinical severity were analysed in an attempt to find clinical guidelines which would predict response to 
primidone or propranolol. However in this group there were no consistent pointers.

We conclude that while propranolol remains the drug of choice, some patients who have contraindications to beta-adrenoreceptor antagonists and some who do not respond adequately to this treatment will benefit from primidone. A useful additive effect of the two drugs has been anecdotally reported, ${ }^{314}$ and this point requires clarification in further controlled trials.

We thank Dr R Langton Hewer for allowing us to study patients under his care; and Dr R Finney of the department of Medical Physics and the staff of the departments of Pharmacy and Clinical Chemistry at Frenchay Hospital for their help and cooperation. Financial support from the Frenchay Postgraduate Bursary Fund is gratefully acknowledged. Propranolol and primidone were generously provided by Imperial Chemical Industries, who also performed the propranolol assays.

\section{References}

' Rajput AH, Offord KP, Beard CM, Kurland LT. Essential tremor in Rochester, Minnesota: a 45 year study. $J$ Neurol Neurosurg Psychiatry 1984;47:466-70.

${ }^{2}$ Winkler GF, Young RR. The control of essential tremor by propranolol. Trans Am Neurol Assoc 1971;96:66-7.

${ }^{3}$ O'Brien MD, Upton AR, Toseland PA. Benign familial tremor treated with primidone. $\mathrm{Br}$ Med J 1981;282: 178-80.
${ }^{4}$ Larsen TA, Calne DB. Essential Tremor. Clin Neuropharmacol 1983;6:185-206.

${ }^{5}$ Cleeves L, Findley LJ. Beta-adrenoreceptor mechanisms in essential tremor: a comparative single dose study of the effect of a non-selective and a beta 2 selective adrenoreceptor antagonist. J Neurol Neurosurg Psychiatry 1984;47:976-82.

${ }^{6}$ Huttunen J, Teravainen H, Larsen TA. Beta adrenoceptor antagonists in essential tremor. Lancet 1984;1:857.

${ }^{7}$ Chakrabarti A, Pearce JMS. Essential tremor: response to primidone. J Neurol Neurosurg Psychiatry 1981;47:650.

${ }^{8}$ Murray TJ. Long term therapy of essential tremor with propranolol. Can Med Ass J 1976;115:892-4.

${ }^{9}$ Morgan MH, Hewer RL, Cooper R. Effect of the beta adrenergic blocking agent propranolol on essential tremor. J Neurol Neurosurg Psychiatry 1973;36:618-24.

${ }^{10}$ Findley LJ, Calzetti S. Double blind controlled study of primidone in essential tremor: preliminary results. $\mathrm{Br}$ Med J 1982;285:608.

"Calzetti S, Findley LJ, Perucca E, Richens A. The response of essential tremor to propranolol: evaluation of clinical variables governing its efficacy. $J$ Neurol Neurosurg Psychiatry 1983;46:393-8.

12 McAllister RG, Markesbery WR, Ware RW, Howel SM. Suppression of essential tremor by propranolol: corre $\square$ lation of effect with drug plasma levels and intensity of beta adrenergic blockade. Ann Neurol 1977; 1:160-6币্

${ }^{13}$ Marsden CD, Obeso JA, Rothwell JC. Benign essentiaf tremor is not a single entity. In: Yahr MD, ed.Currenळ Concepts of Parkinson's Disease and Related Disor? ders. Amsterdam: Excerpta Medica 1983:31-46.

${ }^{14}$ Findley L. Primidone in essential tremor. $\mathrm{Br} \mathrm{Med}$ 1982;285: 1424. 